\title{
Erratum to: Variations in the activity of digestive enzymes along the intestine of the burbot Lota lota expressed by different methods
}

\author{
Galina I. Izvekova • Mikhail M. Solovyev • \\ Elena N. Kashinskaya $\cdot$ Evgeny I. Izvekov
}

Published online: 6 June 2013

(C) Springer Science+Business Media Dordrecht 2013

\section{Erratum to: Fish Physiol Biochem \\ DOI 10.1007/s10695-013-9773-y}

Unfortunately, in enzymes and activity distribution in Table 6, some lines were mismatched in the original publication. The corrected enzymes and activity distribution should read as given in Table 6 .

The online version of the original article can be found under doi:10.1007/s10695-013-9773-y.

G. I. Izvekova $(\bowtie) \cdot$ E. I. Izvekov

Papanin Institute for Biology of Inland Waters, Russian Academy of Sciences, Borok, Nekouzskii raion,

Yaroslavskaya oblast, Moscow 152742, Russia

e-mail: izvekov@ibiw.yaroslavl.ru

M. M. Solovyev · E. N. Kashinskaya

Institute of Systematics and Ecology of Animals, Siberian

Branch of Russian Academy of Sciences, 11 Frunze St.,

Novosibirsk 630091, Russia 
Table 6 Examples of enzyme activity distribution along the digestive tract in fishes

\begin{tabular}{|c|c|c|c|}
\hline Fish species & Enzymes & Activity distribution & References \\
\hline $\begin{array}{l}\text { Nile tilapia Oreochromis niloticus } \\
\text { (omnivorous, mostly herbivorous) }\end{array}$ & $\begin{array}{l}\text { Maltase } \\
\text { Aminopeptidase and } \\
\text { alkaline phosphatase } \\
\text { Lipase } \\
\text { Nonspecific esterases }\end{array}$ & $\begin{array}{l}\text { Segment } 3 \text { out of } 5 \text { (maximum) } \\
\text { Segments } 1-3 \text { out of } 5 \text { (maximum) } \\
\text { Segments } 1 \text { and } 2 \text { out of } 5 \text { (maximum) } \\
\text { Segments } 1-4 \text { out of } 5 \text { (maximum) }\end{array}$ & $\begin{array}{l}\text { Tengjaroenkul } \\
\text { et al. (2000) }\end{array}$ \\
\hline Hybrid tilapia $(O$. niloticus $\times O$. aureus $)$ & Trypsin, amylase, and lipase & Decreases distally & $\begin{array}{l}\text { Sklan et al. } \\
\text { (2004) }\end{array}$ \\
\hline $\begin{array}{l}\text { Gilthead sea bream Sparus aurata } \\
\text { (omnivorous) }\end{array}$ & $\begin{array}{l}\text { Amylase, trypsin, and } \\
\text { chymotrypsin } \\
\text { Carboxypeptidases A and B }\end{array}$ & $\begin{array}{l}\text { Even distribution } \\
\text { Decreases distally }\end{array}$ & $\begin{array}{l}\text { Deguara et al. } \\
\text { (2003) }\end{array}$ \\
\hline Carp Cyprinus carpio (omnivorous) & Proteases & Segments 2 and 4 out of 5 (maximum) & $\begin{array}{l}\text { Jónás et al. } \\
\text { (1983) }\end{array}$ \\
\hline $\begin{array}{l}\text { Silver carp Hypophthalmichthys molitrix } \\
\text { (herbivorous) }\end{array}$ & Proteases & Decreases distally & $\begin{array}{l}\text { Jónás et al. } \\
\text { (1983) }\end{array}$ \\
\hline $\begin{array}{l}\text { Eastern river garfish Hyporhamphus } \\
\text { regularis ardelio (herbivorous) }\end{array}$ & $\begin{array}{l}\text { Amylase, trypsin, } \\
\text { aminopeptidase, and lipase } \\
\text { Maltase }\end{array}$ & $\begin{array}{l}\text { Even distribution } \\
\text { Segment } 1 \text { out of } 4 \text { (maximum) }\end{array}$ & $\begin{array}{l}\text { Day et al. } \\
\text { (2011) }\end{array}$ \\
\hline $\begin{array}{l}\text { Southeastern snub-nosed garfish } \\
\text { Arrhamphus sclerolepis krefftii } \\
\text { (herbivorous) }\end{array}$ & $\begin{array}{l}\text { Amylase, maltase, trypsin, } \\
\text { aminopeptidase, and lipase }\end{array}$ & Even distribution & $\begin{array}{l}\text { Day et al. } \\
\text { (2011) }\end{array}$ \\
\hline $\begin{array}{l}\text { Long tom Strongylura krefftii } \\
\text { (carnivorous) }\end{array}$ & $\begin{array}{l}\text { Amylase } \\
\text { Trypsin } \\
\text { Aminopeptidase } \\
\text { Maltase and lipase }\end{array}$ & $\begin{array}{l}\text { Segment } 1 \text { out of } 4 \text { (maximum) } \\
\text { Segment } 3 \text { out of } 4 \text { (maximum) } \\
\text { Segments } 2 \text { and } 3 \text { out of } 5 \text { (maximum) } \\
\text { Even distribution }\end{array}$ & $\begin{array}{l}\text { Day et al. } \\
\text { (2011) }\end{array}$ \\
\hline $\begin{array}{l}\text { Stout long tom Tylosurus gavialoides } \\
\text { (carnivorous) }\end{array}$ & $\begin{array}{l}\text { Amylase } \\
\text { Maltase } \\
\text { Trypsin and aminopeptidase } \\
\text { Lipase }\end{array}$ & $\begin{array}{l}\text { Segment } 2 \text { out of } 4 \text { (maximum) } \\
\text { Segments } 1-3 \text { out of } 4 \text { (maximum) } \\
\text { Even distribution } \\
\text { Segment } 3 \text { out of } 4 \text { (maximum) }\end{array}$ & $\begin{array}{l}\text { Day et al. } \\
\text { (2011) }\end{array}$ \\
\hline $\begin{array}{l}\text { Spotted sorubim ("pintado" catfish) } \\
\text { Pseudoplatystoma orruscans } \\
\text { (carnivorous) }\end{array}$ & $\begin{array}{l}\text { Amylase } \\
\text { Trypsin } \\
\text { Lipase }\end{array}$ & $\begin{array}{l}\text { Maximum activity in the stomach or } \\
\text { even distribution (depending on diet) } \\
\text { Stomach (maximum) } \\
\text { Segment } 2 \text { out of } 3 \text { (maximum) }\end{array}$ & $\begin{array}{l}\text { Lundstedt et al. } \\
\text { (2004) }\end{array}$ \\
\hline Sheatfish Silurus glanis (carnivorous) & Proteases & Increases distally & $\begin{array}{l}\text { Jónás et al. } \\
\text { (1983) }\end{array}$ \\
\hline
\end{tabular}

